\title{
Exploration on the implementation path of psychological health education improvement of China's young athletes
}

\author{
Zhang Fan ${ }^{1,2, a}$ \\ ${ }^{1}$ Department of Police Skills and Tactics, Nanjing Forest Police College, Nanjing 210023, China \\ ${ }^{2}$ Sports Science postdoctoral programme, Nanjing Normal University, Nanjing 210023, China \\ a zhangfan@nfpc.edu.cn
}

Keywords: Psychological health education, psychological guidance, young athletes, human-oriented concepts.

\begin{abstract}
A young athlete is at first a developing and growing student, then a hard-training athlete who wins the glory for the motherland. Therefore, the psychological health education of young athletes should be based on the contents of the psychological health education of the primary and middle school students. This paper will discuss the contents and implementation strategies of young athletes' psychological health education in detail. Finally, we demonstrate that a series of means could be used in the psychological health education, such as explanation, persuasion, cultivation and games, which were similar as the means of moral education.
\end{abstract}

\section{Introduction}

The excellent athlete should not only have the talent ability to exercise and the unique personality charm, but also have the healthy psychology. Because the training work of young athletes bears the important task of training the qualified athletes, the training work should not only pay attention to constructing their athletic level, enhancing their ideological and moral culture, but also pay attention to their psychological development. Only in this way can young athletes form sound personalities and good morals, truly implementing the training concept of "sports and education". In the process of training, some young athletes have excellent competitive level, and can also obey the rules and discipline of the school, but their psychological endurance is poor; some young athletes are wayward and overbearing, often bullying their classmates and teammates, and it is difficult for them to control their emotions; some young athletes have serious rebellious psychology, which is from refusing the management to affecting their future of sports.

\section{The basic contents of the psychological health education of young athletes}

The core contents of the psychological health education of young athletes include publicizing and promoting the basic contents of the psychological health, creating the corresponding consciousness, mastering simple psychological adjustment measures, understanding mental disorders, and studying the appropriate knowledge of health care. In other words, according to the basic characteristics of the psychological development of young athletes, combining with the realities of learning, life and competition, the psychological health education of young athletes can be summed up as four aspects: learning (training), personality, life, employment, and higher education.

\subsection{The psychological health education of learning and training}

It is undoubtedly the key to promote and develop the psychological health level of young athletes, and its main work is to promote young athletes to enhance their abilities by applying psychological health during learning (training) process. Concretely speaking, it includes two aspects, the positive and the negative: from the positive aspect, the psychological health education of learning (training) focuses on developing young athletes' psychological potential, cultivating their good learning (training) psychological qualities, and guiding young athletes to learn (train); from the negative 
aspect, it helps and guides young athletes to effectively cope with the psychological problems in the process, and effectively cope with such psychological disorders as insufficient motivation and psychological tiredness, and effectively cope with a series of problems, such as improper methods, incorrect habits and weak willpower [1]. Therefore, the core contents of the psychological health education of learning(training) are the following two aspects: one is to help young athletes find suitable ways to improve their psychological health in the learning(training) process, and the other is to supervise and help young athletes to form the corresponding excellent psychological habits.

\subsection{The psychological health education of personality}

In fact, the psychological health education of personality is using the psychological theories and corresponding treatments to promote young athletes to be clearly aware of the basic characteristics of the personality development, to be fully aware of their own psychological characteristics, to develop the healthy self-consciousness, to treat, please, and adjust themselves correctly, and to build up the good outlook on life and value [2]. And its main purposes are: to help young athletes to correctly understand their own personality characteristics, and to objectively understand their own advantages and disadvantages; to analyze the problems and their causes in the personality development; to shape the healthy characters by taking a positive attitude towards yourself, others, the community and society; to understand the specificity of adolescence, the changes and characteristics of physical and mental development, the psychological differences between men and women, and the special psychological self-regulation; and to promote young athletes' interpersonal communication abilities. Therefore, the main contents of the psychological health education of personality should include: guiding young athletes to be good at communicating with others, and to establish good interpersonal relationships with those around them, so as to adapt to the collective life of competitive sports schools; shaping a healthy self; cultivating and exercising their emotions and wills.

\subsection{The psychological health education of life}

The psychological health education of life is using the psychological theories and methods to educate young athletes' psychological problems in their leisure, entertainment, consumption, and daily life which separate from their learning, training, and competition. Its contents conclude: helping young athletes to develop good habits; helping young athletes to arrange their leisure life rather than their learning and training; making the correct financial management and consumption education for young athletes; educating young athletes to make good use of their mobile phones and networks so as to avoid mobile games and online addictions.

\subsection{The psychological health education of higher education and employment}

The psychological health education of higher education and employment is using the principles of psychology to guide young athletes to establish a correct concept of occupation, to help them understand the future occupation they may be engaged in, and to guide them to make ideological and psychological preparations for the future profession, higher education and employment. It mainly covers the following aspects: professional or occupational self-examination counseling, and guiding young athletes to refer to and consult relevant professional teams and institutions of higher education and employment channels, and a series of related information.

\section{Main ways of the psychological health education of young athletes}

The psychological health education of young athletes should be permeated into the whole process of training them, and integrate cultural education, athletic training, school moral education and social practice into it. The specific implementation strategies can be considered from the following aspects.

\subsection{The professional psychological guidance}

\subsubsection{The professional psychological guidance is mainly through the following ways}

The first is the class counseling. Taking classes as the unit, and organizing the teaching contents 
and choosing the activity modes, which is aimed at young athletes of different ages, such as holding psychological courses and related lectures, implementing seminars, scenario settings, and role plays, and carrying out a series of work related to knowledge popularization. Besides, some psychological trainings with definite goals can also be adopted to carry out activities related to the development of psychological qualities [3,4]. The second is the coaching of sports teams. Sports teams can discuss, train and deal with common problems in the training process under the guidance of coaches. And the coaching of sports teams has advantages of both holistic coaching and individual coaching. Because there are some special circumstances during young athletes' training process, they contact coaches for a long time and are affected by it, so the psychological health education is undoubtedly the remedial measure with great developmental potential under this context. The third is the individual coaching. Teachers, coaches and counselors can use their personal communication with young athletes to achieve psychological counseling. There are some of common measures, such as setting up a psychological consultation room, a mailbox and a hotline.

\subsubsection{The common ways of the professional psychological guidance}

The first is the psychological counseling. Young athletes born after 2000 have active thinking and ideas, open vision and strong subject consciousness. Therefore, we cannot treat them like such traditional training model as the corporal punishment. Instead, we should guide them on the basis of understanding. The second is the spiritual cultivation. Psychological health educators in competitive sports schools should be based on teachers' love and many emotional factors so as to promote the healthy development of young athletes' hearts. In other words, through the full display of the inspiring role of personality, personal good qualities and characters, and devotions to young athletes, it will be eager to achieve the effect of the spiritual cultivation. The third is the psychological incentive method. We can encourage and promote the development of young athletes by setting realistic goals. In addition, we can take a series of positive measures and stride forward toward the preset goal. This method highlights the process of constructing psychological goals and taking advantage of some psychological motivations, and its emphasis is on the promotion of young athletes' efforts to set up and achieve psychological goals. The fourth is the psychological control law [5]. In the process of fully mastering the basic characteristics of young athletes' psychological activities, the corresponding management and control should be carried out according to the intensity, characteristics and forms of their psychological activities, such as relaxation training, systematic desensitization training and so on. We can also reduce their inner tension in a systematic and regular manner. The fifth is the psychological training method. We can use the psychological training with a certain target to obtain positive impacts, promote the transformation of the mentality, and then develop to a reasonable psychological level, finally achieving the perfect level of physical and mental development.

\subsection{Carry out psychological health education in the process of moral education}

Actually, both the moral education and psychological health education played a key role in the cultivation of young athletes. The emphasis of the moral education was to internalize the social moral requirements so as to turn them into the personal moral requirements and inner basic literacy cultivation, which was based on a positive attitude. Only by using positive morality and ideology as the guidance through psychological health education could people have a good psychological quality. (Wang Rui,2009). The humanistic quality education called for a full implementation of works concerning the psychological quality, so that a resultant force would be formed in developing integrated personalities of young athlete in an all-round way to satisfy the fundamental requirements of current society for excellent athletic sports talents. The realization of organic interactions between moral education and psychological health education lay in the following aspects:

\subsubsection{The integration of human-oriented concepts}

Due to the general standard's constraint of young athletes in moral education, their personalities were underappreciated. However, the psychological health education puts a strong emphasis on personal dignities and held that all the behaviors affecting their dignity would hamper the normal 
mental development of young athletes. Thus the moral education always viewed the problem of young athletes as the ideological and political one from the perspective of psychological health. Since the party concerned were juveniles, they would inevitably encounter various problems in the growth stage and most of the problems could be classified into the psychological aspect. Once we had a clear understanding, we would not simply regard the prohibited behaviors of young athletes as the result of bad conduct and attribute their introversion and unsociability to the uncommunicative and eccentric disposition.

\subsubsection{The integration of educational functions}

The traditional education usually highlighted the rigid systematic requirements of social standards one-sidedly and ignored the actual psychological requirements of young athletes so that athletes were unwilling to hear the contents said by teachers or coaches. But what they wanted to hear was not mentioned by teachers or coaches. The solution of this problem lay in the concentration on the psychological health education because it emphasized a series of psychological requirements and the mental balance and took the value consciousness strengthening and the obtaining of the sense of achievement as its important purposes. Thus objectively speaking, it's beneficial for the educators to grasp the inner psychological needs of young athletes and their ideological trends. The realization of functions called for the effective integration of traditional and psychological health education in the promotion of moral education to satisfy the requirements on a social level and personal psychological level.

\subsubsection{The integration of educational principles}

Many problems emerged in the implementation of moral education couldn't be simply classified into the psychological education level. We should shape the personality of young athletes by practicing psychological health education, put an emphasis on the introduction of concrete measures of psychological education, gave full play to its reference function and implemented the targeted and diversified educations on the basis of analyzing the mental developmental characteristics of young athletes in different stages [6]. Only by doing so could we ensure the comprehensive and effective development of young athletes in both social level and personal level so as to turn them into the complete social men with healthy psychologies and sound personalities.

\subsection{Practicing psychological health education in the athletic training}

It referred to the strengthening of psychological accomplishments and developing the professional skills and strategies in athletic training so as to give full play to their potentials. It covered the following emphases: 1) Teachers and coaches should take the education of young athletes as the center work, emphasize their dominant roles , faithfully train them and inspire their spontaneities and initiatives so that they would understand that they were the subject of training and mental development. Therefore, they would be fully aware of the dialectical unity among the improvement of psychological quality, the psychological potential exploration, the development of competitive ability as well as the perfection of personality. 2) The problems emerged in the training should be taken as the entry point to eliminate confusions of the young athletes. On the basis of their characteristics, coaches could choose the problems of most concern or the problems what they most wanted to know or to solve as the target, put forward the related cases for discussion or let the young athletes debate over a central problem. 3) The active hint should be given to the young athletes with the principle of encouragement. Coaches ought to do the utmost to satisfy their psychological needs and give them enough space for self-expression [7]. They would get nourishment and happiness of struggling from the complimentary eyes, sincere praises and knowing smiles of the coaches so that they would get into training more actively for the appreciation, support and encourage were the secret for young athletes to overcome the inferiority and build the confidence. 4) Coaches, the models of young athletes, should play an exemplary and demonstration role in the training and affect them in psychological aspect. They should also present a series of excellent characters before their students such as aggressiveness, confidence, self-esteem and self-respect, self-improvement and tolerance. 
Through showing the rational requirements, correct motivation, good and stable emotions as well as the strong will, the coaches exerted a leavening influence on their students in the promotion of sound personalities in the process of imitation.

\subsection{Carry out psychological health education in the school activities}

Undoubtedly, the school activities played a decisive role in carrying out the psychological health education. So we should use various school practical activities such as an educational activity, knowledge-based activity, scientific and technological activities, sports activities and literary and artistic activities to mould psychological qualities. Thus the application of psychological health education in school activities was not only beneficial to the formation of humanistic sentiments and excellent personalities, but also helped them to implement self-education and explore their psychological potentials.

\section{Conclusion}

In order to solve problems emerged in the training, we should follow the rules of psychological development and education, looking forward to the future in line with the teaching ideas of "taking the crown" and the education strategy of "educating people”. Direct or indirect influence would be exerted on the young athletes by systematically adopting various purposeful methods to help and guide them in the improvement of self-recognition, self-control and psychological health. Therefore, the sound personalities would be formed to enhance the comprehensive qualities of the young athletes in an all-round way.

\section{Acknowledgement}

This work was supported in part by the Project of the Fundamental Research Funds for the Central Universities under Grant LGZD201709, in part by the Project of China Postdoctoral Science Foundation under Grant 2017M611849, in part by Jiangsu Qing LAN Project under Grant 2017, and in part by Nanjing Forest police College Teaching Reform Project under Grant ZD17001 \& YB17001.

\section{References}

[1] Zhou, D.W (2016) Psychological education and training strategy of young athletes. Youth Sports, 11, 16-17. (In Chinese)

[2] Sun,B., Xu,L.L. (2007) An Analysis of The Relations Between teenage Athletes' Psychological Health and Stress Events. Journal of Anhui Sports Science, 1, 61-63. (In Chinese)

[3] Liu,G. (2005) The Survey and Analysis of the Young Athletes' (Age From 16 to 22) Psychological health. Journal of Yibin University, 12, 96-98. (In Chinese)

[4] Liu, L. (2013) The influence of athletes locus of control on psychological health. Sports world: Academic Edition, 2, 70-73. (In Chinese)

[5] Gu, F. (2014) Analysis of the relationship between physical exercise and adolescent psychological health. Curriculum education research, 15,233-234. (In Chinese)

[6] Liu, W.G. (2015) The significance and practice of psychological health education for young athletes in sports. Oriental Education, 3, 26-27. (In Chinese) 